\title{
Characteristics and Outcomes of Coronavirus Disease Patients under Nonsurge Conditions, Northern California, USA, March-April 2020
}

\author{
Jessica Ferguson, ${ }^{1}$ Joelle I. Rosser, ${ }^{1}$ Orlando Quintero, Jake Scott, \\ Aruna Subramanian, Mohammad Gumma, Angela Rogers, Shanthi Kappagoda
}

\begin{abstract}
Limited data are available on the clinical presentation and outcomes of coronavirus disease (COVID-19) patients in the United States hospitalized under normal-caseload or nonsurge conditions. We retrospectively studied 72 consecutive adult patients hospitalized with COVID-19 in 2 hospitals in the San Francisco Bay area, California, USA, during March 13-April 11, 2020. The death rate for all hospitalized COVID-19 patients was $8.3 \%$, and median length of hospitalization was 7.5 days. Of the 21 (29\% of total) intensive care unit patients, 3 (14.3\% died); median length of intensive care unit stay was 12 days. Of the 72 patients, $43(59.7 \%)$ had underlying cardiovascular disease and 19 (26.4\%) had underlying pulmonary disease. In this study, death rates were lower than those reported from regions of the United States experiencing a high volume of COVID-19 patients.
\end{abstract}

$\mathrm{H}$ ealth officials in China first reported a cluster of cases of a new acute respiratory illness associated with a seafood market in Wuhan, China, on December 31, 2019 (1). Less than 1 month later, cases of what would become known as coronavirus disease (COVID-19) were reported in patients in northern California, USA (2). In the San Francisco Bay area counties of Alameda and Santa Clara, COVID-19 cases in travelers returning from Wuhan were confirmed on January 28 and January 31, respectively. As of May 5, 2020, a total of 1,809 laboratory-confirmed cases have occurred in Alameda County (population 1.7 million) and 2,555 cases in Santa Clara County (population 1.9 million); however,

Author affiliations: Stanford Health Care, Stanford, California,

USA (J. Ferguson, J.I. Rosser, O. Quintero, J. Scott,

A. Subramanian, A. Rogers, S. Kappagoda); Stanford University, Stanford (M. Gumma)

DOI: https://doi.org/10.3201/eid2608.201776 these numbers probably vastly underestimate the disease incidence because of the lack of widespread testing in the region early in the epidemic $(3,4)$. Studies from China and Europe have described the clinical presentation of COVID-19, but data from the United States are still emerging (5-9). In addition, current data from the United States have primarily come from hospitals working under high-volume or surge conditions. In this study, we describe the characteristics and outcomes of patients hospitalized in northern California with COVID-19 early in the epidemic under nonsurge conditions.

\section{Methods}

\section{Study Design and Oversight}

We conducted a retrospective chart review of demographic and clinical data for patients admitted to our 2 partner institutions, Stanford University Hospital (SUH) and Stanford Health Care-ValleyCare (ValleyCare), during March 13-April 11, 2020, with follow up through May 2, 2020. SUH is an academic medical center with 600 beds, including 119 intensive care unit (ICU) beds, located in Palo Alto, Santa Clara County. ValleyCare is a community hospital with 167 beds, including 22 ICU beds, in Pleasanton, Alameda County. The Stanford Health Care Institutional Review Board approved this study.

\section{Inclusion and Exclusion Criteria}

We sequentially enrolled all patients $\geq 18$ years of age who were hospitalized for $\geq 24$ hours and had reverse transcription PCR (RT-PCR)-confirmed severe acute respiratory syndrome coronavirus 2 (SARS-CoV-2) during the study period. Our study comprised patients who spent $\geq 1$ nights in the hospital; we excluded

${ }^{1}$ These authors contributed equally to this article. 
patients seen only in the emergency department and discharged in $<24$ hours.

\section{Data Sources and Collection}

We used the electronic medical record system, EpicSystems (https://www.epic.com) to extract data on clinical symptoms and signs, laboratory test results, and outcomes. We collected and managed study data using REDCap electronic data capture tools hosted at Stanford University $(10,11)$.

\section{Laboratory Testing}

All laboratory data were ordered as part of routine clinical care. SARS-CoV-2 infection was confirmed using RT-PCR, which was validated on nasopharyngeal, oropharyngeal, endotracheal aspirate, and bronchoalveolar lavage samples.

\section{Definitions}

We recorded the date of the earliest reported symptom. Diabetes was defined by any preadmission medication prescription for diabetes or documented hemoglobin A1C $\geq 6.5 \%$ (reference $<5.7 \%$ ). Admission tests refers to laboratory studies collected within the first 24 hours of admission. We defined admission chest radiograph as one done within 24 hours after hospital arrival and admission chest computed tomography as one performed within 48 hours after hospital arrival. Radiographic findings were based on the radiology report in the electronic medical record. We defined acute respiratory distress syndrome using the Berlin Criteria (presence of acute respiratory failure with bilateral pulmonary infiltrates, ratio of arterial oxygen tension to fraction of inspired oxygen $<300$ with $\geq 5$ $\mathrm{cm}$ water of positive-end expiratory pressure, and absence of cardiogenic pulmonary edema) (12). We defined acute kidney injury as an increase in serum creatinine during admission of 1.5 times baseline (13). We defined cardiomyopathy as an ejection fraction assessed on transthoracic echocardiogram of $<50 \%$ or $\geq 10 \%$ decrease from the baseline ejection fraction if the result of a prior echocardiogram within the past 2 years was available. We defined central line-associated bloodstream infection using National Healthcare Safety Network criteria (14).

\section{Data Analysis}

We conducted all analyses using $\mathrm{R}$ version 3.6.2 (https://www.r-project.org). The 4 patients who remained hospitalized at the end of the study period were right-censored on May 2 and included in length-of-stay calculations. We performed MannWhitney $U$ tests for continuous variables and Fisher exact tests for categorical variables, all using a type I error of 0.05 .

\section{Results}

\section{Demographic Characteristics}

A total of 72 SARS-CoV-2-positive patients were admitted during March 13-April 11, 2020. Twelve were admitted to ValleyCare Hospital and 60 to Stanford Hospital. Twenty-two (30.6\%) patients were Hispanic or Latino, 20 (27.8\%) were Asian or Asian-American, $19(26.4 \%)$ were white, and $4(5.6 \%)$ were black (Table 1). Most (51 [70.8\%]) patients came from stable housing situations with family. Twelve $(16.7 \%)$ lived in a skilled nursing facility, assisted living, group home, or unstable living situation, and 1 (1.4\%) lived alone.

\section{Concurrent Conditions}

Forty-three $(59.7 \%)$ patients had underlying cardiovascular disease, and 19 (26.4\%) had underlying pulmonary disease. Thirty-six percent had no cardiovascular or pulmonary disease. Among the ICU patients, in univariate analysis, only diabetes was significantly associated with ICU admission.

The most common concurrent conditions among all 72 patients were hypertension (36.1\%), hyperlipidemia $(34.7 \%)$, and diabetes $(27.8 \%)$. Twenty-three non-ICU (45.1\%) and 6 ICU (28.6\%) patients had no known cardiovascular disease. The most common respiratory concurrent conditions were asthma (7 patients) or chronic obstructive pulmonary disease (3). Tobacco use did not differ between non-ICU and ICU patients.

Six (8.3\%) patients had an immunocompromising condition. These conditions included 3 with active malignancies, 2 solid organ transplant recipients, and 1 patient with systemic sclerosis.

Before admission, $20(27.8 \%)$ patients had been prescribed azithromycin. Two $(2.8 \%)$ patients had been prescribed hydroxychloroquine to target $\mathrm{CO}$ VID-19. No patients were on long-term hydroxychloroquine for other indications. Twenty-six $(36.1 \%)$ patients, including $5(23.8 \%)$ treated in the ICU, had no known concurrent conditions.

\section{Characteristics at Admission}

At admission, the most common symptoms were fever $(73.6 \%)$, dry cough (58.3\%), and shortness of breath $(56.9 \%)$ (Table 2). Patients also commonly reported nonspecific influenza-like symptoms of fatigue, myalgias, nausea, and diarrhea. Few (5.6\%) patients reported altered sensation of taste or smell. ICU patients were more likely to have fever 
Table 2. Clinical characteristics and laboratory and radiographic findings for COVID-19 patients, northern California, 2020

\begin{tabular}{|c|c|c|c|c|}
\hline \multirow[b]{2}{*}{ Characteristic } & \multicolumn{3}{|c|}{ COVID-19 patients } & \multirow[b]{2}{*}{$p$ value } \\
\hline & All, $n=72$ & Non-ICU, $\mathrm{n}=51$ & $\mathrm{ICU}, \mathrm{n}=21$ & \\
\hline \multicolumn{5}{|l|}{ Symptoms, no. (\%) } \\
\hline Fever & $53(73.6)$ & $37(72.5)$ & $16(76.2)$ & 1.00 \\
\hline Chills & $25(34.7)$ & $15(29.4)$ & $10(47.6)$ & 0.18 \\
\hline Cough, dry & 42 (58.3) & $28(54.9)$ & $14(66.7)$ & 0.44 \\
\hline Cough, productive & $15(20.8)$ & $12(23.5)$ & $3(14.3)$ & 0.53 \\
\hline Shortness of breath & $41(56.9)$ & $29(56.9)$ & $12(57.1)$ & 1.00 \\
\hline Chest pain/pressure & $8(11.1)$ & $6(11.8)$ & $2(9.5)$ & 1.00 \\
\hline Fatigue & $26(36.1)$ & $21(41.2)$ & $5(23.8)$ & 0.19 \\
\hline Myalgias & $32(44.4)$ & $19(37.3)$ & $13(61.9)$ & 0.07 \\
\hline Arthralgias & $1(1.4)$ & $1(2.0)$ & 0 & 1.00 \\
\hline Headache & $14(19.4)$ & $9(17.6)$ & $5(23.8)$ & 0.53 \\
\hline Sore throat & 10 (13.9) & $5(9.8)$ & $5(23.8)$ & 0.14 \\
\hline Nasal congestion/rhinorrhea & $7(9.7)$ & $3(5.9)$ & $4(19.0)$ & 0.18 \\
\hline Nausea & $17(23.6)$ & $15(29.4)$ & $2(9.5)$ & 0.13 \\
\hline Vomiting & $7(9.7)$ & $7(13.7)^{\prime}$ & 0 & 0.01 \\
\hline Diarrhea & $19(26.4)$ & $13(25.5)$ & $6(28.6)$ & 0.78 \\
\hline Altered sense of taste/smell & $4(5.6)$ & $3(5.9)$ & $1(4.8)$ & 1.00 \\
\hline Other† & $16(22.2)$ & $11(21.6)$ & $5(23.8)$ & $\mathrm{NP}$ \\
\hline \multicolumn{5}{|l|}{ Vital signs } \\
\hline Medium max temp in first $24 \mathrm{~h},{ }^{\circ} \mathrm{C}$ (IQR) & $38.1(37.3-38.8)$ & $37.8(37.2-38.7)$ & $38.6(38.6-39.3)$ & $<0.05$ \\
\hline Temperature $\geq 38.2^{\circ} \mathrm{C}$, no. $(\%)$ & $34(47.2)$ & $19(37.3)$ & $15(71.4)$ & $<0.05$ \\
\hline \multicolumn{5}{|l|}{ Room air SaO2, no. (\%) } \\
\hline $\mathrm{SaO} 2 \geq 94$ & $42(58.3)$ & $36(70.6)$ & $6(28.6)$ & $<0.05$ \\
\hline Median $\mathrm{SaO} 2$ & $30(41.7)$ & $15(29.4)$ & $15(71.4)$ & \\
\hline$<94$ RR (IQR) & $20(18-22)$ & $19(18-20)$ & $22(18-27)$ & $<0.05$ \\
\hline \multicolumn{5}{|l|}{ Laboratory results, median (IQR) $\ddagger$} \\
\hline Leukocytes, $\mathrm{K} / \mu \mathrm{L}$ & $5.6(4.3-7.8)$ & $5.7(4.4-8.1)$ & $5.2(4.0-7.0)$ & 0.40 \\
\hline ANC, $n=71$ & $3,890(2,705-5,835)$ & $3,875(2,630-5,725)$ & $4140(2930-6430)$ & 0.42 \\
\hline ALC, $n=71$ & $910(580-1,235)$ & $915(592-1,335)$ & $890(520-1,090)$ & 0.47 \\
\hline Platelets, $\mathrm{K} / \mu \mathrm{L}$ & $194(160-256)$ & $198(162-265)$ & $183(157-250)$ & 0.40 \\
\hline Sodium, $\mathrm{mmol} / \mathrm{L}$ & $136(133-138)$ & $136(132-139)$ & $136(134-137)$ & 1.00 \\
\hline Potassium, mmol/L & $3.8(3.7-4.2)$ & $3.9(3.7-4.2)$ & $3.8(3.6-4.0)$ & 0.31 \\
\hline Creatinine, mg/dL & $0.89(0.67-1.07)$ & $0.89(0.73-1.07)$ & $0.89(0.66-1.07)$ & 0.69 \\
\hline Glucose, mg/dL & $108(98-124)$ & $107(96-120)$ & $114(102-147)$ & 0.18 \\
\hline AST, U/L & $45.5(31.8-63.5)$ & $45.0(29.0-59.5)$ & $52.0(38.0-82.0)$ & 0.04 \\
\hline$A L T, U / L$ & $36.5(23.8-56.2)$ & $35.0(22.5-51.5)$ & $49.0(34.0-58.0)$ & 0.09 \\
\hline CK, total, U/L & $119(55-360)$ & $53(48-70)$ & $282(174-774)$ & 0.01 \\
\hline $\mathrm{LDH}, \mathrm{U} / \mathrm{L}$ & 394 (251-492) & $344(250-442)$ & $430(299-522)$ & 0.03 \\
\hline Ferritin, ng/mL & 824 (453-1643) & $612(304-1030)$ & $1422(817-1944)$ & 0.04 \\
\hline CRP $>0.5$ ng/dL, no./total (\%) & $36 / 41(87.8)$ & $21 / 26(80.8)$ & $15 / 15(100)$ & 0.14 \\
\hline IL-6 >5 pg/mL, no./total (\%) & $5 / 7(71.4)$ & $3 / 3(100)$ & $2 / 4(50.0)$ & 0.43 \\
\hline Procalcitonin $>0.5 \mathrm{ng} / \mathrm{mL}$, no./total $(\%)$ & $4 / 47(8.5)$ & $3 / 33(9.1)$ & $1 / 14(7.1)$ & 1.0 \\
\hline D-dimer $>0.5 \mu \mathrm{g} / \mathrm{mL}$, no./total $(\%)$ & 20/26 (76.9) & $14 / 19(73.7)$ & 6/7 (85.7) & 1.0 \\
\hline Troponin $>0.055 \mathrm{ng} / \mathrm{mL}$, no./total $(\%)$ & $2 / 45(4.4)$ & $1 / 31(3.2)$ & $1 / 14(7.1)$ & 0.53 \\
\hline \multicolumn{5}{|l|}{ Radiology, no. (\%) } \\
\hline \multicolumn{5}{|l|}{ Chest radiograph } \\
\hline Diffuse/patchy bilateral infiltrates & $45(62.5)$ & $26(51.0)$ & $19(90.5)$ & $<0.05 \S$ \\
\hline Focal consolidation & $11(15.3)$ & $9(17.6)$ & $2(9.5)$ & NP \\
\hline Pleural effusion & $4(5.6)$ & $2(3.9)$ & $2(9.5)$ & \\
\hline Clear & $11(15.3)$ & $11(21.6)$ & 0 & \\
\hline Other $\mathbb{1}$ & $5(6.9)$ & $4(7.8)$ & $1(4.8)$ & \\
\hline \multicolumn{5}{|l|}{ Chest computed tomography scan } \\
\hline Diffuse/multifocal/GGO/opacities & $11(15.3)$ & $8(15.7)$ & $3(14.3)$ & \\
\hline Diffuse consolidations & $4(5.6)$ & $3(5.9)$ & $1(4.8)$ & \\
\hline Focal consolidation & $2(2.8)$ & $2(3.0)$ & 0 & \\
\hline
\end{tabular}

*ALC, absolute lymphocyte count; ALT, alanine aminotransferase; ANC, absolute neutrophil count; AST, aspartate aminotransferase; CK, creatinine kinase; COVID-19, coronavirus disease; CRP, C-reactive protein; GGO, ground glass opacities; IL-6, interleukin-6; IQR, interquartile range; LDH, lactate dehydrogenase; NP, test not performed; RR, respiratory rate.

†Altered mental status, dizziness, night sweats, anorexia, and abdominal pain

†Reference ranges: leukocytes, $4.0-11.0 \mathrm{~K} / \mu \mathrm{L} ; \mathrm{ANC}, 1,700-6,700$ cells $/ \mu \mathrm{L} ; \mathrm{ALC}, 1,000-3,000$ cells $/ \mu \mathrm{L} ;$ platelets, $150-400 \mathrm{~K} / \mu \mathrm{L} ;$ sodium, $135-145$ $\mathrm{mmol} / \mathrm{L}$; potassium, 3.5-5.5 mmol/L; creatinine, 0.67-1.17 mg/dL; glucose, 70-100 mg/dL; AST, 10-50 U/L; ALT, 10-50 U/L; CK, total <190 U/L; LDH, 135-225 U/L; ferritin 30-400 ng/mL; CRP $<0.5 \mathrm{ng} / \mathrm{dL}$; IL-6, $\leq 5 \mathrm{pg} / \mathrm{mL}$; procalcitonin, $\leq 0.5 \mathrm{ng} / \mathrm{mL}$; D-dimer, $<0.5 \mu \mathrm{g} / \mathrm{mL}$; troponin $<0.055 \mathrm{ng} / \mathrm{mL}$. $\S$ Compares diffuse/patchy bilateral infiltrates with all other categories combined.

IBibasilar opacities and interstitial markings. 
documented within 24 hours after admission and had higher temperatures recorded. Of 48 patients who had a multiplex PCR-based respiratory viral panel performed within 24 hours after admission, 2 had a viral co-infection (1 patient with respiratory syncytial virus and 1 with both respiratory syncytial virus and rhinovirus).

Abnormal results of chest imaging were more common in patients requiring ICU admission. Among patients admitted to the ICU, $19(90.5 \%)$ had an initial chest radiograph with diffuse or patchy bilateral opacities, compared with $26(51.0 \%)$ of non-ICU patients. None of the patients admitted to the ICU had normal-appearing chest radiograph result at admission. Overall, very few patients had a chest computed tomography scan performed within the first 48 hours of hospitalization.

\section{Treatments}

Patients most commonly received remdesivir (44.4\% of all patients and $76.2 \%$ of ICU patients), azithromycin, or both during hospitalization (Table 3). Four ICU patients received tocilizumab, and 1 received leronlimab. Among the 12 patients seen at ValleyCare,

\begin{tabular}{|c|c|c|c|c|}
\hline \multirow[b]{2}{*}{ Variable } & \multicolumn{3}{|c|}{ COVID-19 patients } & \multirow[b]{2}{*}{$\mathrm{p}$ value } \\
\hline & All, $n=72$ & Non-ICU, $n=51$ & $\mathrm{ICU}, \mathrm{n}=21$ & \\
\hline \multicolumn{5}{|l|}{ Complications, no. (\%) } \\
\hline Acute respiratory distress syndrome & $13(18.0)$ & 0 & $13(61.9)$ & NP \\
\hline Arrhythmia† & $6(8.3)$ & 0 & $6(28.6)$ & \\
\hline Ventilator- or hospital-associated pneumonia & $5(6.9)$ & 0 & $5(23.8)$ & \\
\hline Acute kidney injury & $4(5.6)$ & 0 & $4(19.0)$ & \\
\hline Catheter-related bloodstream infection & $2(2.8)$ & 0 & $2(9.5)$ & \\
\hline Cardiomyopathy $\ddagger$ & $2(2.8)$ & 0 & $2(9.5)$ & \\
\hline \multicolumn{5}{|l|}{ Highest level of oxygen support required, no. (\%) } \\
\hline None & $29(40.3)$ & $28(54.9)$ & $1(4.8)$ & Referent \\
\hline Oxygen by nasal cannula & $22(30.6)$ & $21(41.2)$ & $1(4.8)$ & 1.0 \\
\hline High-flow nasal cannula & $2(2.8)$ & $1(2.0)$ & $1(4.8)$ & 0.13 \\
\hline Nonrebreather mask & $6(8.3)$ & $1(2.0)$ & $5(23.8)$ & $<0.05$ \\
\hline Mechanical ventilation & $13(18.1)$ & 0 & $13(61.9)$ & NP \\
\hline Median duration of mechanical ventilation, $d \S(I Q R)$ & & NP & $17(13-29)$ & NP \\
\hline \multicolumn{5}{|l|}{ Interventions, no. (\%) } \\
\hline Use of a paralytic agent & $7(9.7)$ & 0 & $7(33.3)$ & NP \\
\hline Use of proning & $6(8.3)$ & $1(2.0)$ & $5(23.8)$ & \\
\hline Tracheostomy & $6(8.3)$ & 0 & $6(28.6)$ & \\
\hline Use of vasopressors & $13(18.1)$ & 0 & $13(61.9)$ & \\
\hline Use of renal replacement therapyI & $4(5.6)$ & 0 & $4(19.0)$ & \\
\hline Inhaled nitric oxide & $4(5.6)$ & 0 & $4(19.0)$ & \\
\hline \multicolumn{5}{|l|}{ Treatment, no. (\%) } \\
\hline Azithromycin & $33(45.8)$ & $19(37.3)$ & $14(66.7)$ & $<0.05$ \\
\hline Remdesivir & $32(44.4)$ & $15(29.4)$ & $16(76.2)$ & $<0.05$ \\
\hline Hydroxychloroquine & $16(22.2)$ & $11(21.6)$ & $5(23.8)$ & 1.0 \\
\hline Systemic glucocorticoids & $5(6.9)$ & $3(5.9)$ & $2(9.5)$ & 0.63 \\
\hline Tocilizumab & $4(5.6)$ & 0 & $4(19.0)$ & $<0.05$ \\
\hline Other\# & $11(15.3)$ & $8(15.7)$ & $3(14.3)$ & NP \\
\hline Any antimicrobial drug & $48(66.7)$ & $28(54.9)$ & $19(90.5)$ & $<0.05$ \\
\hline Any antifungal drug & $1(1.4)$ & $\begin{array}{c}0 \\
0\end{array}$ & $1(4.8)$ & 0.29 \\
\hline \multicolumn{5}{|l|}{ Median length of stay, ${ }^{* *} \mathrm{~d}(\mathrm{IQR})$} \\
\hline Hospitalization & $7.5(4-13)$ & $5(3-9)$ & $17(11-30)$ & \\
\hline ICU & NP & NP & $12(5-28)$ & \\
\hline \multicolumn{5}{|l|}{ Disposition, no. (\%) } \\
\hline \multicolumn{5}{|l|}{ Discharged from hospital } \\
\hline Home & $53(73.6)$ & $43(84.3)$ & $10(47.6)$ & $0.35 \dagger \dagger$ \\
\hline SN/LTAC facility & $9(12.5)$ & $5(9.8)$ & $4(19.0)$ & \\
\hline Died or discharged with hospice & $6(8.3)$ & $3(5.9)$ & $3(14.3)$ & \\
\hline Remains hospitalized & $4(5.6)$ & 0 & $4(19.0)$ & \\
\hline \multirow{2}{*}{\multicolumn{5}{|c|}{$\begin{array}{l}{ }^{*} \text { COVID-19, coronavirus disease; ICU, intensive care unit; IQR, interquartile range; LTAC, long-term acute care; NP, test not performed; SN, skilled } \\
\text { nursing. } \\
\text { †Includes } 2 \text { atrial fibrillation with rapid ventricular response, } 2 \text { supraventricular tachycardia, } 2 \text { bradycardia. }\end{array}$}} \\
\hline & & & & \\
\hline \multicolumn{5}{|c|}{$\begin{array}{l} \pm N e w \text { ejection fraction }<50 \% \text { after previously normal ejection fraction on echocardiogram in the preceding } 2 \text { y and/or }>10 \% \text { decrease in ejection fraction } \\
\text { from baseline. }\end{array}$} \\
\hline \multirow{2}{*}{\multicolumn{5}{|c|}{ 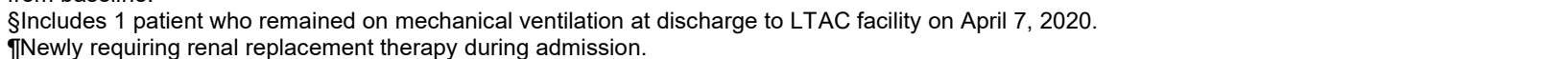 }} \\
\hline & & & & \\
\hline $\begin{array}{l}\text { \#LInc, } n=11 \text {; leronlimab, } n=1 \text {. } \\
{ }^{* *} \text { Length of stay includes } 4 \text { patients who remained hospitalized }\end{array}$ & the & & & \\
\hline
\end{tabular}


in addition to supportive care, 11 (91.7\%) received hydroxychloroquine, 11 (91.7\%) received zinc, and 5 $(41.7 \%)$ received azithromycin. No patients received convalescent plasma, lopinavir/ritonavir, chloroquine, or intravenous gamma globulin during the study period. A trial of prone positioning was used for 2 hypoxic, nonintubated patients, in accordance with institutional protocol (15).

\section{Complications}

No major complications developed in the patients who never required ICU care during hospitalization (non-ICU patients) (Table 3). Acute respiratory distress syndrome developed in 13 (61.9\%) ICU patients. No patients were treated with intravenous pulmonary vasodilators or extracorporeal membrane oxygenation. Arrhythmias developed in 6 ICU patients, 4 with supraventricular tachycardia, including atrial fibrillation or atrial flutter, and 2 with bradycardia, including complete heart block requiring a permanent pacemaker that developed in 1 .

\section{Outcomes}

Five $(6.9 \%)$ patients died, and 1 patient was discharged to hospice. Fifty-three $(73.6 \%)$ patients were discharged home, and $9(12.5 \%)$ were discharged to a skilled nursing facility or long-term acute care hospital. At the end of the study period (May 2, 2020), 4 remained hospitalized awaiting placement in a skilled nursing facility or long-term acute care hospital. Of the 6 patients who died or were discharged to hospice, median age was 83.5 years. Median length of hospitalization for all patients was 7.5 days (interquartile range [IQR] 4-13 days).

Among ICU patients, 3 (14.3\%) died; median length of hospitalization was 17 days (IQR 11-30 days). Thirteen $(61.9 \%)$ ICU patients required mechanical ventilation for a median of 17 days (IQR 1329 days), and $6(28.6 \%)$ patients underwent tracheostomy. All 4 patients who remained hospitalized had required ICU admission; however, all had improved by the end of the study period, and none still required mechanical ventilation or ICU level of care.

\section{Discussion}

We found a lower overall death rate $(8.3 \%)$ than for the largest US studies thus far, which reported $17.5 \%-21 \%$ death rates (J.A. Lewnard et al., unpub. data, https://doi.org/10.1101/2020.04.12.20062943; C.M. Petrilli et al., unpub. data, https://doi.org/ 10.1101/2020.04.08.20057794) (16). The death rate for ICU patients of $14.3 \%$ was also lower than previously reported rates within the United States $(45 \%-50 \%)$
(C.M. Petrilli et al., unpub. data, https://doi.org/1 $0.1101 / 2020.04 .08 .20057794)(17)$. These results are based on censoring 4 patients who remained hospitalized at the end of the study period, all of whom no longer required ICU level of care and awaited placement in rehabilitation or long-term acute care facilities. Although our sample size is small, this difference in death rates might be attributed to nonsurge conditions. Patient volumes did not exceed normal operating capacity in the 2 hospitals during the study period, which might signify that patients were admitted who might not merit hospitalization in conditions where hospital beds were limited. Disease severity was probably lower in the population in our study; $71 \%(51 / 72)$ of patients required only nasal cannula supplemental oxygen or no oxygen during admission. In addition, the substantial number of patients treated with remdesivir might have contributed to the lower death rate. Preliminary data from recent clinical trials suggest remdesivir use may be associated with reduced mortality $(18,19)$.

The presenting symptoms and laboratory findings of the patients in our study are similar to those noted in the studies from China published earlier in the COVID-19 pandemic despite the finding that our patient population probably had greater racial and ethnic diversity (6-9). As seen in prior studies, respiratory complaints were the most common presenting symptoms; however, 5 (6.9\%) patients in our study did not have respiratory symptoms of cough or shortness of breath. This finding emphasizes the importance of capturing nonrespiratory symptoms on COVID-19 screening questionnaires.

California in general, and the San Francisco Bay area in particular, have had a longstanding housing affordability crisis (20). Seven (9.7\%) patients in our study lacked a safe place to isolate at home because of crowded living conditions (no separate bedroom), living with an immunocompromised person, or both. These circumstances also might have contributed to lower hospitalization death rates because patients with mild disease required hospital admission.

One important context for this study is the difference in the standard of care at the 2 institutions. When our institutions began seeing COVID-19 patients, the Centers for Disease Control and Prevention and the World Health Organization had published clinical care guidelines emphasizing supportive care as the standard of care and recommended using experimental therapies only as part of a randomized controlled trial $(21,22)$. Both of our study sites are involved in clinical trials of the novel 
antiviral agent remdesivir but began enrolling at different times: March 14 at SUH and April 9 at ValleyCare. This difference in implementation led to nonuniform use of hydroxychloroquine, azithromycin, and zinc between SUH and ValleyCare. At both study sites, azithromycin was commonly prescribed to outpatients before admission, despite lack of evidence of clinical efficacy. Detailed national guidelines from the Society for Critical Care Medicine were published on March 20 and from the Infectious Disease Society of America on April $11(23,24)$. Notable differences in the standard of care were seen even between our 2 affiliated hospitals, perhaps reflecting the initial lack of national guidelines.

Our study has several limitations. Overall case numbers were low, probably because of early and decisive public health interventions in our community (25). This observational study is not powered or designed to analyze treatment efficacy of the experimental therapies given. Analysis of the efficacy of remdesivir, received by most critically ill patients in this cohort, will be conducted as part of a multisite clinical trial. Four patients remained hospitalized at the conclusion of the study period, and final outcomes could therefore not be reported. Thus, the duration of hospitalization is weighted toward patients who had shorter admissions and outcomes of a subset of prolonged hospital courses were not captured. Our results most likely are not generalizable to hospitals with excessive COVID-19 caseloads or with fewer resources for high acuity patients.

In summary, we found that under nonsurge conditions, the overall death rate and the death rate for ICU patients were lower than those previously reported in the United States. The differences in treatment strategy between the 2 hospitals in this study highlight the need for standardized, well-publicized guidelines for new pathogens early on in an epidemic.

J.I.R. is supported by National Institutes of Health Training Grant 5T32AI052073-14.

A.S. and S.K. are involved in a clinical trial of remdesivir sponsored by Gilead Pharmaceuticals.

\section{About the Authors}

Dr. Ferguson is an infectious diseases fellow at Stanford Health Care. Her research interests include immunocompromised and transplant infectious diseases. Dr. Rosser is an infectious diseases fellow at Stanford Health Care. Her primary research interest is studying the impact of climate change and globalization on emerging infectious diseases.

\section{References}

1. World Health Organization. Novel Coronavirus (2019-NCoV) Situation Report 1. 21 January 2020 [cited 2020 May 11]. https:/ / www.who.int/docs/default-source/ coronaviruse/situation-reports/20200121-sitrep-12019-ncov.pdf

2. Bialek S, Boundy E, Bowen V, Chow N, Cohn A, Dowling N, et al.; CDC COVID-19 Response Team. COVID-19 Response Team. Severe outcomes among patients with coronavirus disease 2019 (COVID-19) - United States, February 12-March 16, 2020. MMWR Morb Mortal Wkly Rep. 2020;69:343-6. https:/ / doi.org/10.15585/mmwr.mm6912e2

3. ArcGIS. Alameda County COVID-19 dashboard [cited 2020 May 5]. https://ac-hcsa.maps.arcgis.com/apps/opsdashboard/index.html\#/948c67558cff414dbbee1a78fcbab1c9

4. Santa Clara County Public Health Emergency Operations Center. Santa Clara County coronavirus (COVID-19) data dashboard [cited 2020 May 5]. https:/ / www.sccgov.org/ sites/covid19/Pages/dashboard.aspx

5. Grasselli G, Zangrillo A, Zanella A, Antonelli M, Cabrini L, Castelli A, et al.; COVID-19 Lombardy ICU Network. Baseline characteristics and outcomes of 1591 patients infected with SARS-CoV-2 admitted to ICUs of the Lombardy region, Italy. JAMA. 2020;323:1574. https://doi.org/10.1001/jama.2020.5394

6. Guan WJ, Ni ZY, Hu Y, Liang WH, Ou CQ, He JX, et al.; China Medical Treatment Expert Group for Covid-19. Clinical characteristics of coronavirus disease 2019 in China. N Engl J Med. 2020;382:1708-20. https:/ / doi.org/10.1056/ NEJMoa2002032

7. Li LQ, Huang T, Wang YQ, Wang ZP, Liang Y, Huang TB, et al. COVID-19 patients' clinical characteristics, discharge rate, and fatality rate of meta-analysis. J Med Virol. 2020;92:577-83 [Epub ahead of print]. https:/ / doi.org/10.1002/jmv.25757

8. Ruan Q, Yang K, Wang W, Jiang L, Song J. Clinical predictors of mortality due to COVID-19 based on an analysis of data of 150 patients from Wuhan, China. Intensive Care Med. 2020 Mar 3 [Epub ahead of print]. https:// doi.org/10.1007/s00134-020-05991-x.

9. Yang X, Yu Y, Xu J, et al. Clinical course and outcomes of critically ill patients with SARS-CoV-2 pneumonia in Wuhan, China: a single-centered, retrospective, observational study. Lancet Respir Med. 2020 Feb 24 [Epub ahead of print]. https://doi.org/10.1016/S2213-2600(20)30079-5

10. Harris PA, Taylor R, Minor BL, Elliott V, Fernandez M, $\mathrm{O}^{\prime} \mathrm{Neal} \mathrm{L}$, et al.; REDCap Consortium. The REDCap consortium: building an international community of software platform partners. J Biomed Inform. 2019;95:103208. https://doi.org/10.1016/j.jbi.2019.103208

11. Harris PA, Taylor R, Thielke R, Payne J, Gonzalez N, Conde JG. Research electronic data capture (REDCap) - a metadata-driven methodology and workflow process for providing translational research informatics support. J Biomed Inform. 2009;42:377-81. https://doi.org/10.1016/ j.jbi.2008.08.010

12. Ranieri VM, Rubenfeld GD, Thompson BT, Ferguson ND, Caldwell E, Fan E, et al.; ARDS Definition Task Force. Acute respiratory distress syndrome: the Berlin definition. JAMA. 2012;307:2526-33.

13. Lopes JA, Jorge S. The RIFLE and AKIN classifications for acute kidney injury: a critical and comprehensive review. Clin Kidney J. 2013;6:8-14. https:/ / doi.org/10.1093/ckj/ sfs160

14. Centers for Disease Control and Prevention. 2020 National Healthcare Safety Network (NHSN) patient safety 
component manual. 2020 Jan [cited 2020 Apr 14]. https://www.cdc.gov/nhsn/pdfs/pscmanual/pcsmanual_ current.pdf

15. Stanford Medicine COVID-19 Critical Care Task Force. Proning non-intubated patient [cited 2020 May 11]. https:/ / sites.google.com/view/stanford-covid/home/ proning-non-intubated-patient

16. Richardson S, Hirsch JS, Narasimhan M, Crawford JM, McGinn T, Davidson KW, et al.; and the Northwell COVID-19 Research Consortium. Presenting characteristics, comorbidities, and outcomes among 5700 patients hospitalized with COVID-19 in the New York City area. JAMA. 2020. https://doi.org/10.1001/jama.2020.6775

17. Arentz M, Yim E, Klaff L, Lokhandwala S, Riedo FX, Chong M, et al. Characteristics and outcomes of 21 critically ill patients with COVID-19 in Washington state. JAMA. 2020;323:1612. https://doi.org/10.1001/jama.2020.4326

18. Gilead. Gilead announces results from phase 3 trial of investigational antiviral remdesivir in patients with severe COVID-19 [cited 2020 May 4]. https:/ / www.gilead.com/ news-and-press/press-room/press-releases/2020/4/ gilead-announces-results-from-phase-3-trial-of-investigational-antiviral-remdesivir-in-patients-with-severe-covid-19

19. National Institute of Allergy and Infectious Diseases. NIH clinical trial shows remdesivir accelerates recovery from advanced COVID-19 [cited 2020 May 4]. http:/ / www.niaid. nih.gov/news-events/nih-clinical-trial-shows-remdesiviraccelerates-recovery-advanced-covid-19

20. California Department of Housing and Community Development. California's housing future: challenges and opportunities. Final statewide housing assessment 2025. February 2018 [cited 2020 Apr 14]. https:/ / www.hcd. ca.gov/policy-research/plans-reports/docs/SHA_Final_ Combined.pdf

21. Centers for Disease Control and Prevention. Coronavirus disease 2019 (COVID-19). Interim clinical guidance for management of patients with confirmed coronavirus disease (COVID-19) [cited 2020 Mar 28]. https:/ / www.cdc.gov/ coronavirus/2019-ncov/hcp/clinical-guidance-managementpatients.html

22. World Health Organization. Clinical management of severe acute respiratory infection when novel coronavirus $(\mathrm{NCoV})$ infection is suspected [cited 2020 Mar 28]. https:/ / www. who.int/publications-detail/clinical-management-of-severeacute-respiratory-infection-when-novel-coronavirus-(ncov)infection-is-suspected

23. Alhazzani W, Møller MH, Arabi YM, Loeb M, Gong MN, Fan E, et al. Surviving Sepsis Campaign: guidelines on the management of critically ill adults with coronavirus disease 2019 (COVID-19). Crit Care Med. 2020 Mar 27 [Epub ahead of print]. https://doi.org/10.1097/CCM.0000000000004363

24. Bhimraj A, Morgan RL, Hirsch Shumaker A, Lavergne V, Baden L, Cheng VCC, et al. Infectious Diseases Society of America guidelines on the treatment and management of patients with COVID-19. Clin Infect Dis. 2020 Apr 27 [Epub ahead of print]. http:// doi.org/10.1093/cid/ciaa478

25. City and County of San Francisco Department of Public Health. Order of the health officer no. C19-07b [cited 2020 May 11]. https://www.sfdph.org/dph/alerts/files/ HealthOfficerOrder-C19-07b-ShelterInPlace-03312020.pdf

Address for correspondence: Shanthi Kappagoda, Stanford Health Care, Division of Infectious Diseases and Geographic Medicine, 300 Pasteur Dr, L-134, Stanford, CA 94305, USA; email: skappago@stanford.edu

\section{EID Podcast Developing Biological Reference Materials to Prepare for Epidemics}

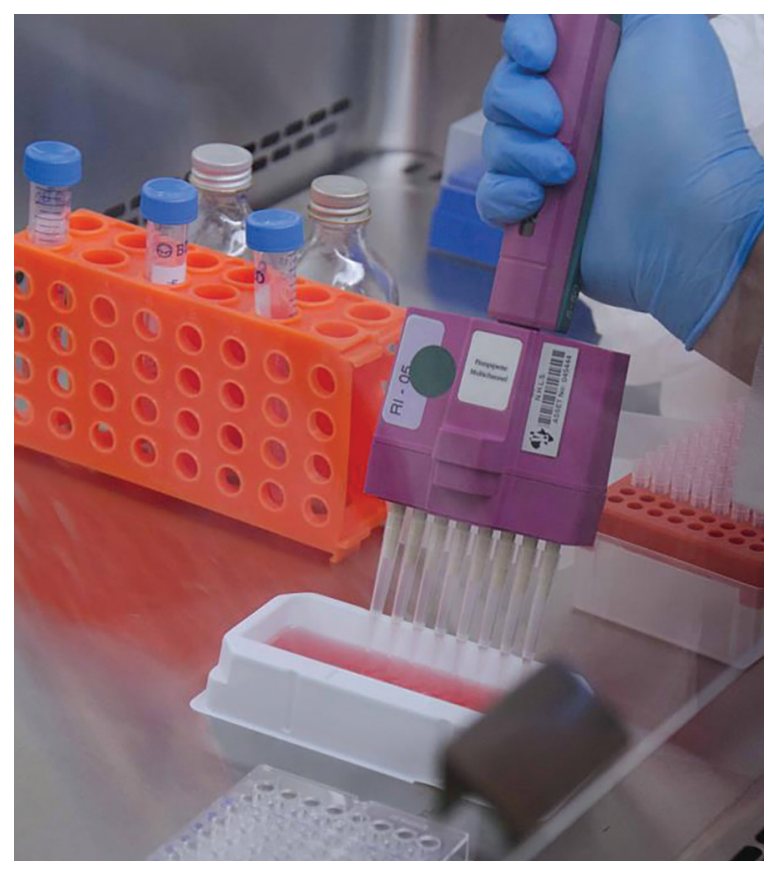

Having standard biological reference materials, such as antigens and antibodies, is crucial for developing comparable research across international institutions. However, the process of developing a standard can be long and difficult.

In this EID podcast, Dr. Tommy Rampling, a clinician and academic fellow at the Hospital for Tropical Diseases and University College in London, explains the intricacies behind the development and distribution of biological reference materials.

\section{Visit our website to listen: https://go.usa.gov/xyfJX}

\section{EMERGING \\ INFECTIOUS DISEASES}

